\title{
Evaluating the provision of flexible learning for children at risk of primary school dropout in Malawi
}

\begin{abstract}
Communities in Malawi selected 15 children deemed "at-risk" - predominantly orphans - in Class 6 of each of 20 intervention schools to receive learning materials, support from the community and a school "buddy." An experimental evaluation found that dropout was reduced by $45 \%$ across intervention schools compared to 20 control schools. The program had spillover effects, indirectly reducing dropout among older pupils in the class not deemed at-risk. These findings imply that age, and not orphanhood, was the main indicator of vulnerability and that when targeting criteria are considered carefully, flexible learning programs can reduce dropout substantially among vulnerable children.
\end{abstract}

Keywords: HIV \& AIDS; Africa; dropout, vulnerability; flexible learning; orphanhood. 


\section{Introduction}

Malawi is one of several sub-Saharan African countries whose education systems are characterized by very high initial enrolments in primary schooling but with high repetition and dropout leading to low completion rates, and by falling transition rates to secondary and tertiary education (Lewin, 2007, p. 17). According to survival rates calculated in 2010, approximately half (52\%) of all enrolled pupils fail to reach their final year of the primary school cycle (Ministry of Education Science and Technology, 2010). Approximately 20 percent of children of primary school-going age do not attend school (NSO, 2000, 2005; NSO \& UNICEF, 2007). Consequently, Malawi is not yet on track to reach Universal Primary Education (UPE) by 2015 and the 2011 Education for All Global Monitoring Report calls for such countries to improve school retention and progression by raising educational quality and providing 'additional support and learning opportunities for the poorest and most vulnerable learners' (UNESCO, 2011 p.97).

Two questions arise: Who are the poorest and most vulnerable learners in Malawi? And what sort of additional support and learning opportunities do they need? One commonly identified group of vulnerable learners is children affected by HIV and AIDS either because they are orphans or because they live with chronically ill parents or guardians (Pridmore, 2007; Bennell, 2005). Educational responses to the impact of HIV and AIDS on children's access to learning include: subsidization of school-related costs to address poverty and promote demand; school feeding programs and health initiatives to encourage enrolment and reduce absenteeism; community mobilization and support; identification, monitoring and follow-up of vulnerable children, including school-based counseling and psychosocial support; open and flexible modes of delivery to reach 
marginalized children, as well as more general improvements in the quality of education (Pridmore \& Yates, 2005; Bennell, 2005; Boler \& Carroll, 2003; Boler \& Jellema, 2005; Carr-Hill, Katabaro, Katahoire, \& Oulai, 2002; Hepburn, 2001; Kelly, 2000; Rispel, 2006).

Among these strategies, Pridmore (2005) argues that there is much unexplored potential in open, distance and flexible learning (ODFL). In Malawi, ODFL has mainly been used to widen and support access to secondary education through now-defunct distance education study centers (Murphy, 1993), to train teachers (Streuli \& Moleni, 2007) and more recently through the Interactive Radio Instruction (IRI) program Tikwere ("let's climb"), targeted at the first three years of primary school. However, a recent analysis (Yates, 2008) indicates that although some statements about ODL are integrated into mainstream education planes, Malawi does not yet have specific policies on open or distance education.

In addition to support for learning, vulnerable children living in high HIV prevalence areas also need support for living (Isikawa et al, 2010; UNAIDS, 2001). This dual need has been addressed in the Circles of Support initiative developed by the Soul City Institute in South Africa and piloted in Botswana, Namibia and Swaziland. This initiative mobilizes networks of family, friends and neighbors to develop and undertake small actions to support vulnerable learners. A qualitative evaluation suggests that this initiative has been successful in supporting vulnerable children to continue with their schooling (Dlamini, 2005).

In this article we describe and evaluate the SOFIE (Strengthening Open and Flexible learning to Increase Educational access) program, which aimed to tackle 
problems of dropout and grade repetition in an area of high HIV prevalence by complementing government schooling with additional support for learning typical of ODFL initiatives and with support networks more common to programs targeted at children made vulnerable by HIV and AIDS.

Despite a substantial literature on policy options and strategies to mitigate the impact of HIV and AIDS on children's access to education there is a lack of evidence from experimental studies. Indeed, such evidence is lacking for the support of orphans and vulnerable children in general (Schenk, 2009) and yet it is critical for evidence-based policy decisions.

\subsection{The SOFIE Project}

The SOFIE Project took place in Phalombe and Mzimba South districts in Malawi. Case studies in these districts (Jere, 2008) found that irregular attendance and dropout was common among vulnerable children (Pridmore \& Jere, 2011) whose high aspirations and recognition of the opportunities afforded by education were often overwhelmed by competing household demands for resources and children's time. The case studies found that school children, especially girls, were required to care for siblings and chronically sick parents, which contributed to poor school attendance. Intrahousehold discrimination resulted in a lack of encouragement for orphans, especially double orphans, to attend school. Girls suffered disproportionately from this discrimination, being required to do chores instead of going to school, or being pushed into early marriage. Such problems were exacerbated by a community-wide loss of social cohesion in HIV-stressed communities which left some orphans uncared for and open to abuse. 
At the school level, policies were found to be unsupportive of orphans and poor children. Pupils were often sent home if they were unable to buy a uniform, or were poorly dressed, or did not have adequate notebooks or pens. No systematic attempts were made to identify vulnerable children, beyond that required for donor-supported school feeding programmes. The few initatives present to assist with the welfare of vulnerable children were piecemeal, limited in scope and largely community-led; guidance and counselling were not provided.

In this context, there is clearly great potential to increase support for the education of vulnerable children and this was the aim of the SOFIE project intervention. The intervention is described in detail elsewhere (see Pridmore \& Jere, 2011) and summarized here. Communities were asked to select 15 pupils who they considered at-risk of dropout from school. Each at-risk pupil received a 'school-in-a-bag' that contained English and Mathematics national curriculum textbooks and supplemental self-study learner guides. School buddies (mentor pupils) were recruited to support at-risk pupils' learning, to follow them up when they were absent and if required, to carry self-study guides to class teachers for grading. Local secondary-school leavers were recruited as volunteers to run clubs for vulnerable children identified as at-risk. The purpose of the clubs was to provide additional learning opportunities and support outside of school, in a friendly and informal environment. Each club leader received training, a club leader's manual and a portable resources kit (a 'school-in-a-box') to set up club activities. Teachers also received training and were responsible for keeping a register of all pupils identified as atrisk and for regularly monitoring their progress and participation in class activities.

Each school had a SOFIE sub-committee including School Management 
Committee (SMC) and Parent Teachers Association (PTA) representatives, the school's headteacher, the class teacher and club leader. The committee identified vulnerable children for inclusion on the at-risk register based on criteria they developed in training workshops. Criteria were emphasized that reflected the Government of Malawi's (2005) definition of a vulnerable child and included family and household characteristics (living with elderly, infirm or chronically ill adults or in child-headed households), schoolrelated factors (grade repetition, irregular attendance, poor performance and participation in class) and general welfare (socially isolation, experiencing hungry and/or poor health, being poorly dressed, lacking schools materials).

An examination of the community's process of selecting vulnerable children in this project has the potential to inform our understanding of the concepts of orphanhood and vulnerability more broadly. Both of these concepts have both evolved over time (Sherr, Varrall, Mueller, \& One, 2008) in part to reflect a recognition that children living in areas of high HIV prevalence are often most vulnerable when their parents are sick and in need of care (Foster \& Williamson, 2000) as well as in the aftermath of a parental death. Revised definitions also acknowledge the greater risk for orphans living in femaleheaded and child-headed households. However, the use of the term vulnerability remains problematic because community perceptions frequently differ from those used to target programs (Schenk, 2008; Skinner et al., 2006) and may relate more to a perceived lack of basic needs than to visible indicators of vulnerability such as orphanhood. Understanding of vulnerability also rarely focuses on educational outcomes, although it is recognized that continued school attendance can mitigate against poor psychosocial outcomes for vulnerable children (Jukes et al., 2008a, Jukes et al., 2008b; Ishikawa et al., 2010a; 
Bhargava, 2005). One aim of our research is to understand how perceived vulnerability in an educational context relates to observed risk of dropout, in order to understand how programs to support vulnerable children can best be targeted (Andrews, Skinner, \& Zuma, 2006).

Given the relatively small number of target beneficiaries, we were also interested in how benefits of the program may spill over to other children in the same school. There is documented evidence in experimental evaluations of materials and approaches introduced by education programs finding their way from intervention to control schools (Crouch, Korda, \& Mumo, 2009). If spillover can take place between schools, it seems more likely that such a spillover effect could take place within a single school to benefit children not targeted by the program.

In sum, this paper presents an evaluation of the SOFIE project in Malawi which aims to contribute to the evidence base on supporting learning of the poorest and most vulnerable pupils. The intervention complements face-to-face classroom delivery of the curriculum with distance learning resources and psychosocial and welfare support. The primary research questions addressed by the evaluation were:

(1) What is the impact of the SOFIE flexible learning model on school dropout (the primary outcome), educational achievement and grade promotion (the secondary outcomes)? To what extent does this impact extend to children in the same school who are not targeted by the SOFIE program?

(2) What criteria do communities use to identify vulnerable children and to what extent do these criteria match those predictive of dropout risk?

\section{Methods}




\subsection{Participants}

Participants were 2,767 children aged 8-20 years ( $M=13.4$ years) in 40 Malawian primary schools in two districts, one from the south (Phalombe) and one from the north (Mzimba). There were 1,355 girls (49.0\%) in the sample (see Figure 1).

\subsection{Schools}

Enrolment in the study schools ranged from 350 pupils to almost 3000 pupils. Many schools were severely understaffed with 93 pupils per teacher in Mzimba South and 111 pupils per teacher in Phalombe. The vast majority of teachers were fully qualified. Overall, just under a third (31\%) of the teaching staff was female, with only two female headteachers.

\subsection{Randomization}

Forty primary schools were randomly sampled to take part in the trial, 20 from each of the two participating districts. The sampling frame consisted of all 70 government schools in Phalombe district and all 60 government schools in the Traditional Authority of M'mbwela, a sub-unit of Mzimba District. For each district, schools were ranked in quintiles based on the percentage of Class 8 pupils selected for secondary school - a proxy for school quality - with two intervention and two control schools being selected at random in each quintile.

\subsection{Sample Size}

Sample size calculations indicated that 40 schools would be sufficient to detect a reduction in dropout from $20 \%$ to $9 \%$ in 15 children deemed at-risk in each school with $80 \%$ power, assuming an intra-class correlation coefficient of 0.05 . 


\subsection{Data Collection Instruments}

The SOFIE project adapted national grade-equivalent exam papers in English and Mathematics as educational assessments. Following the poor performance of many pupils in the baseline, a supplementary test paper was developed for the post-test exam with items suitable for a wider range of ability (Grade 3 - Grade 7).

A structured pupil questionnaire was designed to gather data on pupil characteristics. Pupils completed the questionnaire themselves with help from a member of the research team. Checklists were designed to collate data from school records and SOFIE monitoring forms. Semi-structured key informant interview schedules and focus group discussion guides were developed to gather qualitative data on the implementation and impact of the SOFIE model.

\subsection{Data Collection}

Data were collected from schools during three visits, one at baseline in November 2008, one mid-term and one at the end-line in October 2009. Qualitative data were collected at the mid-point and more extensively during the final survey in the four casestudy schools through interviews with Class 6 teachers, club leaders, headteachers and SOFIE sub-committee chairs, focus group discussions with community members, informal discussions with buddies, school staff and parents/guardians of pupils who were deemed at-risk and had dropped out of school and through half-day workshops held with at-risk pupils. The workshops involved participatory activities designed to explore pupils' perspectives on schooling and the SOFIE Project. Twenty two pupils deemed at-risk were purposively selected and took part in in-depth interviews. 


\subsection{Data Analytic Plan}

The data analysis aimed to assess differences in outcomes between the intervention and control group as an estimate of the impact of the program. The first set of analyses estimated the overall differences between intervention and control group. Random school effects were included to account for clustering of outcomes at the school level.

For four binary outcomes - indicating whether children dropped out, repeated Class 6, were absent in the final survey or were promoted to Class 7 - logistic regression was conducted to determine the impact of the program. For example

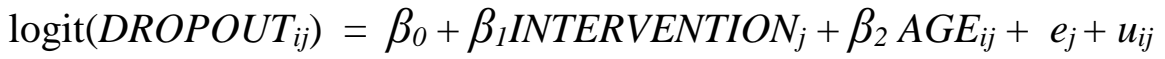

For exam scores, multilevel linear regression analyses were used.

EXAM SCORE $_{1 i j}=\beta_{0}+\beta_{1}$ INTERVENTION $_{j} \beta_{2}$ MATH SCORE $_{0 i j}+\beta_{3}$ ENGLISH $\operatorname{SCORE}_{0 i j} e_{j}+u_{i j}$

$E X A M S C O R E_{t i j}=$ The outcome score on one of the assessments (Mathematics, English or the Supplementary Exam) at time $\mathrm{t}$ for student $i$ in school $j$; $\mathrm{t}=0$ at baseline and $\mathrm{t}=1$ at follow-up

The aim of the second set of analyses was to estimate the impact of the program on the sub-group of children who were deemed at-risk by their community and thus selected to take part in the SOFIE club. This analysis was problematic because no comparison at-risk group was selected in the control schools for ethical reasons. We used 
propensity score matching (Luellen, Shadish, \& Clark, 2005) to create a comparison subgroup in control schools, an effective methods for identifying program-related sub-group impacts (Schochet \& Burghardt, 2007). The propensity score for being included in SOFIE clubs in the intervention schools was derived from baseline characteristics with relatively few missing values that could have been observed by community members and thus may have served as the basis for their assessment of children as being at-risk. These propensity scores were then used to match SOFIE club members to a control group member with a similar propensity score. Propensity score matching was conducted without replacement using psmatch2 command of Stata (StataCorp, 2009).

The analyses of Equations (1) and (2) were then repeated including terms for children deemed at-risk by their community and the interaction between at-risk group and intervention. Equations (1) and (2) were also repeated separately for each sub-groups defined by perceived risk status. In all analyses, where baseline characteristics were found to differ between intervention and control groups, these covariates were included to produce a second adjusted estimate of program effects.

Qualitative interviews and FGDs were recorded and transcribed by research assistants in the field and, where necessary, subsequently translated into English. Transcripts were analyzed and coded using Nvivo (QSR International Pty Ltd, 2008) for coding and analysis. Permission to conduct the research was granted by the Ministry of Education Science and Technology in Malawi and by the London Institute of Education Ethics Committee.

\section{Results}

Table 1 shows the baseline characteristics of children in control and intervention 
schools. These data were taken from school records (orphan status, repeating grades and transferring from another school), and from the pupil questionnaire administered in October 2008 and in November 2009 (absent during survey, reasons for not learning, missing breakfast on the morning of the questionnaire, receiving financial assistance for education from someone outside the family). Variables described in Table 1 are either from 2008, before the intervention began, or are variables assumed to be unaffected by the intervention (e.g. orphan status). 


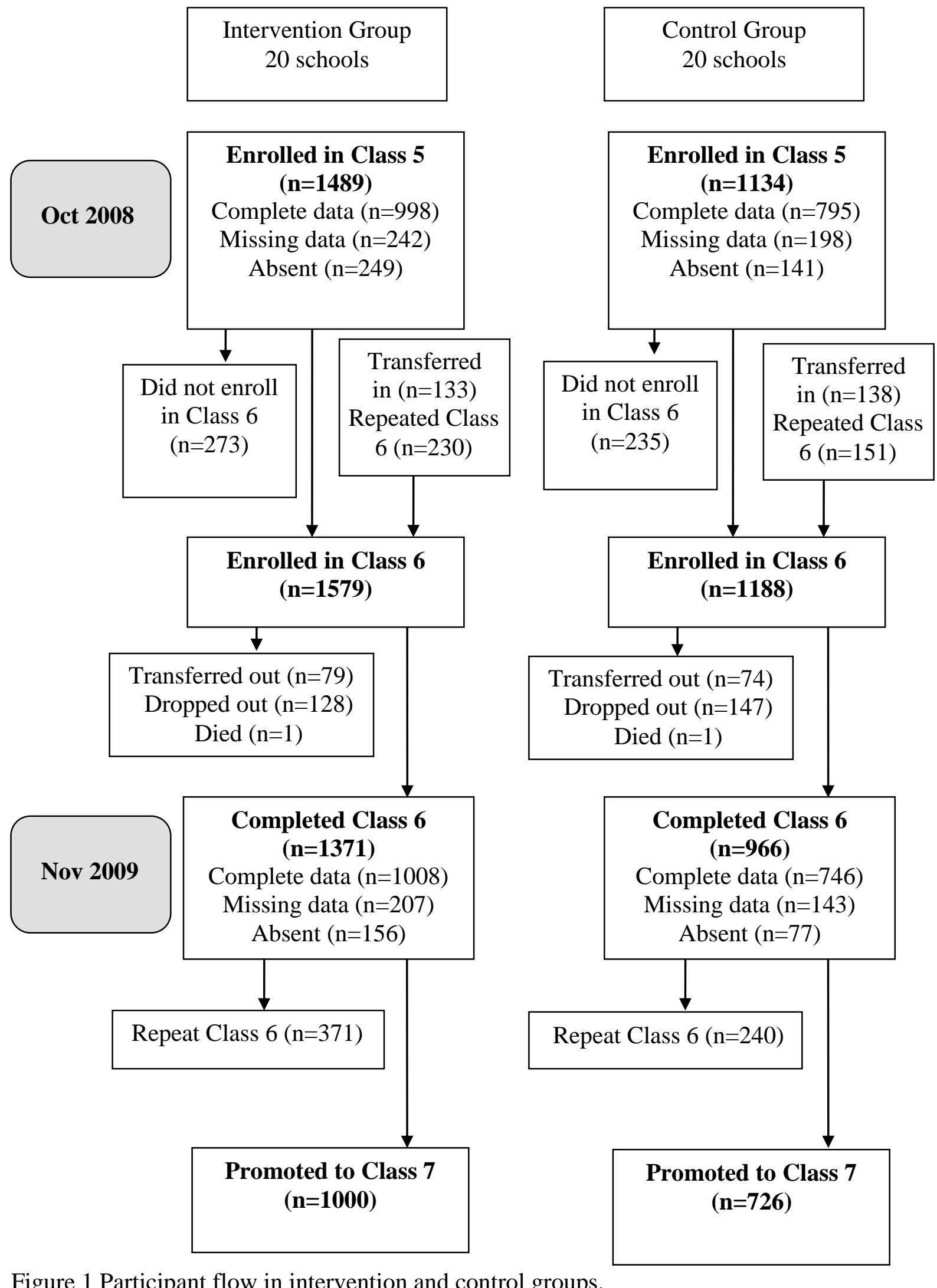


Table 1 shows randomization was somewhat successful in creating a balance between experimental groups. The only significant difference between groups was among the subgroup of pupils $(n=1662)$ who took the baseline English exam. Scores on this exam were higher among the control group. There were apparently large differences in rates of children missing breakfast (around 60\% in both 2008 and 2009 for the intervention group and less than $40 \%$ in the control group) but these differences did not approach significance.

\subsection{Missing Data}

Data were missing at baseline in 2008 and at follow-up in 2009 for many reasons (see Figure 1 for participant flow chart). In 2008 we collected data from children in Class 5 of all participating schools. Many children were attending other schools and later transferred to study schools ( $\mathrm{n}=271)$, or were in Class 6 in 2008 and subsequently repeated $(n=381)$ or were absent on the day of data collection $(n=390)$. Of the children who entered Class 6 many were not present at the final survey because they had dropped out of school $(n=275)$, had transferred to another school $(n=153)$, had died $(n=2)$ or were absent on the day of the survey $(n=233)$. For subsequent analyses, we used multiple imputation techniques (Royston, 2004; Van Buuren, Boshuizen, \& Knook, 1999) to predict missing values based on observable characteristics of each child. 
Table 1. Baseline characteristics of Children and Schools in Intervention and Control Group.




Table 2. Predictors of being included in the at-risk group in intervention schools

\begin{tabular}{lcc}
\hline Predictor & Odds Ratio & Confidence Interval \\
\hline Age (Yrs) & 1.02 & $(0.893-1.169)$ \\
Male & 1.13 & $(0.758-1.687)$ \\
Single Orphan (School Records) & $40.43^{* * *}$ & $(24.387-67.032)$ \\
Double Orphan (School Records) & $140.27^{* * *}$ & $(58.34-337.23)$ \\
Paternal Orphan 2008 (Self- & & \\
Report) & $2.65^{* * *}$ & $(1.443-4.865)$ \\
Maternal Orphan 2008 (Self- & & \\
Report) & 1.73 & $(0.824-3.632)$ \\
No Breakfast 2009 & $1.96^{* * *}$ & $(1.309-2.932)$ \\
Received Assistance 2009 & 1.25 & $(0.816-1.911)$ \\
Parents Employed 2009 & 0.54 & $(0.249-1.179)$ \\
Absent in 2008 & 1.04 & $(0.375-2.893)$ \\
Partial Data in 2008 & $0.38^{* * *}$ & $(0.136-1.078)$ \\
Repeated St. 6 & 0.97 & $(0.374-2.500)$ \\
Transferred into St. 6 & $0.23^{* * *}$ & $(0.080-0.669)$ \\
\hline Observations & 1,579 & \\
Number of schools & 20 & \\
\hline
\end{tabular}

$* * * \mathrm{p}<0.01, * * \mathrm{p}<0.05, * \mathrm{p}<0.1 \quad 95 \%$ confidence intervals in parentheses

\subsection{Characteristics of children deemed at-risk by their community}

To create a comparison group in control schools for the children deemed at-risk in intervention schools we first constructed a model, based on observable characteristics of pupils that would have been available to communities. We used these characteristics to predict community selection of pupils for the at-risk group. Table 2 shows that children listed as double orphans in school records were 140 times more likely than non-orphans to be included in this group and thus included in SOFIE clubs (59 of 81 double orphans were chosen). Single orphans were 40 times more likely to be selected. In addition, children who reported being a paternal orphan or having missed breakfast on the day of the survey were more likely to be included. Children who transferred into the school in the year of the study were less likely to be included, presumably because the selection 
committee members did not yet know these children well. The propensity score

procedure selected 259 at-risk children to match the 259 SOFIE club members in the

intervention schools.

Table 3. Baseline characteristics of children in Intervention and Control groups deemed at-risk by their communities.

Female

\begin{tabular}{cccccccc} 
n & \multicolumn{3}{c}{ Intervention Group } & & \multicolumn{3}{c}{ Control Group } \\
& Freq & $\%$ & $\mathrm{n}$ & & Freq & $\%$ & $\mathrm{n}$ \\
\cline { 2 - 4 } \cline { 5 - 7 } & 117 & $(45.2 \%)$ & 259 & & 117 & $(45.2 \%)$ & 259
\end{tabular}

From School Register:

Single orphan

Double orphan

Repeating St 6 (2009)

Transferred in (2009)

From Pupil

Questionnaires:

Maternal orphan

Paternal orphan

Reasons given for not learning in 2008:

Teacher absent

No text books

No note books

Hungry

Punished

No breakfast (2008)***

Received assistance (2008)**

No breakfast (2009)*

Received assistance (2009)

Parent employed (2009)

Absent at Survey (2008)

$\begin{array}{ccccccc}496 & 151 & (61.4 \%) & 246 & 160 & (64.0 \%) & 250 \\ 496 & 59 & (24.0 \%) & 246 & 48 & (19.2 \%) & 250 \\ 518 & 51 & (19.7 \%) & 259 & 45 & (17.4 \%) & 259 \\ 518 & 16 & (6.2 \%) & 259 & 21 & (8.1 \%) & 259\end{array}$

267

$$
\begin{array}{lll}
48 & (48.3 \%) & 128 \\
83 & (64.8 \%) & 128
\end{array}
$$

$37 \quad(26.6 \%) \quad 139$

$\begin{array}{lll}89 & (64.0 \%) & 139\end{array}$

$\begin{array}{llclccc}267 & 14 & (10.9 \%) & 128 & 12 & (8.6 \%) & 139 \\ 267 & 24 & (21.6 \%) & 128 & 30 & (18.8 \%) & 139 \\ 267 & 54 & (42.2 \%) & 128 & 63 & (45.3 \%) & 139 \\ 267 & 32 & (25.0 \%) & 128 & 21 & (15.1 \%) & 139 \\ 267 & 24 & (18.8 \%) & 128 & 17 & (12.2 \%) & 139 \\ 270 & 89 & (68.5 \%) & 130 & 63 & (45.0 \%) & 140 \\ & & & & & & \\ 271 & 58 & (44.3 \%) & 131 & 86 & (61.4 \%) & 140 \\ 414 & 89 & (55.2 \%) & 212 & 117 & (44.1 \%) & 202 \\ & & & & & & \\ 410 & 98 & (46.7 \%) & 210 & 116 & (58.0 \%) & 200 \\ 412 & 13 & (6.2 \%) & 211 & 17 & (8.5 \%) & 201 \\ 518 & 45 & (17.4 \%) & 259 & 33 & (12.7 \%) & 259\end{array}$

Age (years)

\begin{tabular}{cccc}
518 & $\mathrm{M}$ & $\mathrm{SD}$ & $\mathrm{n}$ \\
\cline { 2 - 4 } & 13.72 & $(1.48)$ & 259
\end{tabular}

\begin{tabular}{ccc}
$\mathrm{M}$ & $\mathrm{SD}$ & $\mathrm{n}$ \\
\hline 13.49 & $(1.69)$ & 259 \\
5.21 & $(3.97)$ & 159
\end{tabular}

English exam score

$\frac{(2008) * *}{* * * \mathrm{p}<0.01, * * \mathrm{p}<0.05, * \mathrm{p}<0.1}$ 
Table 3 summarizes the background characteristics in these two groups. As with the full sample, the control group outperformed the intervention group in the baseline English exam. In addition, the intervention group were more likely to have missed breakfast on the day of the survey in $2008(\mathrm{p}<.05)$ and in $2009(\mathrm{p}<.1)$ but less likely to report that their family received financial assistance in $2008(\mathrm{p}<.05)$.

The above quantitative data helps identify the criteria used by communities to select at-risk children. In addition, qualitative data provided valuable information about the process of selection of at-risk children. Informants frequently reported that being selected as an at-risk child was highly sought after. One teacher in Phalombe district reported the effects of this desire for inclusion during the selection process, saying "Most community members were pressurising us to select their own children." One SOFIE committee chair mentioned the repercussions after selection had taken place: "[We suffer] insults from community during follow-up visits...we are accused of favouritism." Accusations of favouritism were perhaps exacerbated by the relatively small size of the SOFIE clubs compared to the perceived need. 
Table 4. Description of main outcome variables in Intervention and Control Groups overall and among children deemed at-risk by their communities.

\begin{tabular}{|c|c|c|c|c|c|c|c|}
\hline \multirow{2}{*}{ Overall } & \multirow[t]{2}{*}{$\mathrm{n}$} & \multicolumn{3}{|c|}{ Intervention Group } & \multicolumn{3}{|c|}{ Control Group } \\
\hline & & Freq & $\%$ & $\mathrm{n}$ & Freq & $\%$ & $\mathrm{n}$ \\
\hline Dropped out (2009) & 2,767 & 128 & $(8.1 \%)$ & 1,579 & 147 & $(12.4 \%)$ & 1,188 \\
\hline Repeated St 6 (2009-10) & 2,767 & 371 & $(23.5 \%)$ & 1,579 & 240 & $(20.2 \%)$ & 1,188 \\
\hline Absent at final survey & 2,767 & 156 & $(9.9 \%)$ & 1,579 & 77 & $(6.5 \%)$ & 1,188 \\
\hline \multirow[t]{2}{*}{ Promoted to St. 7 (2010) } & 2,767 & 1000 & $(63.3 \%)$ & 1,579 & 726 & $(61.1 \%)$ & 1,188 \\
\hline & & M & SD & $\mathrm{n}$ & M & SD & $\mathrm{n}$ \\
\hline Maths exam score (2009) & 2,028 & 7.45 & (5.93) & 1,166 & 6.06 & $(3.97)$ & 862 \\
\hline English exam score (2009) & 2,028 & 10.28 & $(5.57)$ & 1,166 & 10.65 & $(5.00)$ & 862 \\
\hline Advanced exam score (2009) & 2,028 & 8.87 & (3.38) & 1,166 & 8.85 & $(3.01)$ & 862 \\
\hline \multicolumn{8}{|l|}{ Children deemed at-risk } \\
\hline Dropped out (2009) & 518 & 13 & $(5.0 \%)$ & 259 & 29 & $(11.2 \%)$ & 259 \\
\hline Repeated St 6 (2009-10) & 518 & 56 & $(21.6 \%)$ & 259 & 48 & $(18.5 \%)$ & 259 \\
\hline Absent at final survey & 518 & 20 & $(7.7 \%)$ & 259 & 13 & $(5.0 \%)$ & 259 \\
\hline \multirow[t]{2}{*}{ Promoted to St. 7 (2010) } & 518 & 180 & $(69.5 \%)$ & 259 & 168 & $(64.9 \%)$ & 259 \\
\hline & & M & SD & $\mathrm{n}$ & M & SD & $\mathrm{n}$ \\
\hline Maths exam score (2009) & 412 & 7.05 & $(5.41)$ & 213 & 6.005 & $(4.09)$ & 199 \\
\hline English exam score (2009) & 412 & 10.25 & $(5.57)$ & 213 & 10.46 & $(4.75)$ & 199 \\
\hline Advanced exam score (2009) & 412 & 8.98 & (3.19) & 213 & 8.61 & (2.94) & 199 \\
\hline
\end{tabular}

\subsection{Impact of the SOFIE Program}

Outcome variables are summarized overall and for children deemed as at-risk in

Table 4. Differences between the Intervention group and the Control group are evident from the percentage of children dropping out and in the Mathematics exam score, both in the overall sample and in the at-risk sub-groups. Tables 5, 6 and 7 present estimates of the program impact. In all tables we present unadjusted estimates and adjusted estimates controlling for baseline covariates. 
Table 5. Summary of significant program impacts overall and by risk sub-groups.

\begin{tabular}{|c|c|c|c|c|}
\hline \multirow[t]{2}{*}{ Outcome: } & Dropout & Dropout & Maths & Maths \\
\hline & $\begin{array}{l}\text { Unadjusted } \\
\text { Odds Ratio }\end{array}$ & $\begin{array}{l}\text { Adjusted } \\
\text { Odds Ratio }\end{array}$ & $\begin{array}{l}\text { Unadjusted } \\
\text { Coeff }\end{array}$ & $\begin{array}{l}\text { Adjusted } \\
\text { Coeff }\end{array}$ \\
\hline $\begin{array}{l}\text { Overall } \\
\mathrm{n}=2,767\end{array}$ & $\begin{array}{c}0.55^{* * *} \\
(0.367-0.827)\end{array}$ & $\begin{array}{c}0.46^{* * *} \\
(0.311-0.673)\end{array}$ & $\begin{array}{c}0.63 \\
(-0.124-1.380)\end{array}$ & $\begin{array}{c}0.59 \\
(-0.253-1.442)\end{array}$ \\
\hline $\begin{array}{l}\text { Deemed at-risk by } \\
\text { community } \\
\mathrm{n}=518\end{array}$ & $\begin{array}{c}0.40^{* *} \\
(0.189-0.838)\end{array}$ & $\begin{array}{c}0.40^{* *} \\
(0.171-0.943)\end{array}$ & $\begin{array}{c}0.91 * * \\
(0.085-1.733)\end{array}$ & $\begin{array}{c}0.83^{*} \\
(-0.071-1.733)\end{array}$ \\
\hline $\begin{array}{l}\text { Not deemed at- } \\
\text { risk } \\
\mathrm{n}=2,249\end{array}$ & $\begin{array}{c}0.61 * * \\
(0.401-0.921)\end{array}$ & $\begin{array}{c}0.51 * * * \\
(0.336-0.760)\end{array}$ & $\begin{array}{c}0.61 \\
(-0.151-1.375)\end{array}$ & $\begin{array}{c}0.58 \\
(-0.194-1.354)\end{array}$ \\
\hline
\end{tabular}

Table 5 summarizes significant program impacts. Unadjusted estimates suggest that the intervention reduced dropout overall by $45 \%(\mathrm{OR}=0.55)$. The reduction in dropout was greater among children deemed at-risk $(\mathrm{OR}=0.40)$ than children not deemed at-risk $(\mathrm{OR}=0.61)$ although the difference between these two figures was not significant. To assess robustness, the randomly seeded propensity matching procedure was rerun 1000 times with the estimate of the impact of treatment on the at-risk group being recalculated each time. These estimates were combined using Monte-Carlo methods. The resulting estimated odds ratio for the impact of the intervention on dropout among at-risk children was 0.43 ( $95 \%$ CI $0.19-0.98 ; \mathrm{p}=.044)$. Reassuringly, this value is similar to that $(\mathrm{OR}=0.40)$ derived from the matching procedure used to generate the above results.

Adjusted estimates for baseline covariates resulted in similar or slightly larger program effects. Unadjusted estimates also suggested a significant program effect on 
mathematics scores for the at-risk group (an increase in 0.91 marks out of 24) but not for children not at-risk nor for the overall sample. Adjusted estimates suggest a reduced program effect of 0.83 marks for the at-risk group with borderline significance $(p=.071)$ when controlling for covariates.

Table 6 presents the full regression models for academic progression variables. As discussed above, the program had a significant impact on dropout but not on other variables. There was no significant interaction between intervention and at-risk subgroups suggesting that the program did not have a significantly different impact on target at-risk children compared to children not at risk. This interaction term was subsequently dropped from all models. Age was significantly associated with all outcomes. Despite being in the same grade, children's age varied significantly with most children being aged between 11 years and 17 years of age. Looking first at Model (1), each additional year of age was associated with a $57 \%$ increase in the chances of dropping out $(\mathrm{OR}=1.57)$. The significant Age x Intervention interaction in Model (2) indicates that the program was particularly effective in reducing the dropout of older children (see Figure 2). Models (3)(5) show that Age was also associated with poorer academic outcomes for repetition, absenteeism and promotion. However, there was no significant program impact specific to older children on these latter outcomes. 
Table 6. Logistics regression equation estimates of the impact of the program on academic progression outcomes

\begin{tabular}{|c|c|c|c|c|c|}
\hline Outcome & $\begin{array}{c}(1) \\
\text { Dropped Out }\end{array}$ & $\begin{array}{c}(2) \\
\text { Dropped Out }\end{array}$ & $\begin{array}{c}(3) \\
\text { Repeated }\end{array}$ & $\begin{array}{c}\text { (4) } \\
\text { Absent at final } \\
\text { survey }\end{array}$ & $\begin{array}{c}(5) \\
\text { Promoted }\end{array}$ \\
\hline \multicolumn{6}{|l|}{ Without Covariates: } \\
\hline \multirow[t]{2}{*}{ Intervention } & $0.55 * * *$ & $0.55 * * *$ & 1.43 & 1.76 & 1.18 \\
\hline & $(0.367-0.827)$ & $(0.367-0.827)$ & $(0.785-2.596)$ & $(0.852-3.641)$ & $(0.791-1.766)$ \\
\hline Deemed at-risk by & 0.77 & 0.77 & 0.9 & 0.72 & $1.34 * * *$ \\
\hline community & $(0.539-1.090)$ & $(0.539-1.090)$ & $(0.694-1.155)$ & $(0.483-1.076)$ & $(1.085-1.664)$ \\
\hline \multicolumn{6}{|l|}{ With Covariates: } \\
\hline \multirow[t]{2}{*}{ Intervention } & $0.46 * * *$ & 8.39 & 1.3 & 1.74 & 1.38 \\
\hline & $(0.311-0.673)$ & $(0.652-107.862)$ & $(0.677-2.511)$ & $(0.861-3.530)$ & $(0.866-2.208)$ \\
\hline \multirow{2}{*}{$\begin{array}{l}\text { Deemed at-risk by } \\
\text { community }\end{array}$} & $0.49 * * *$ & $0.48 * * *$ & 1.15 & 1.42 & 1.26 \\
\hline & $(0.286-0.831)$ & $(0.280-0.816)$ & $(0.786-1.672)$ & $(0.808-2.500)$ & $(0.908-1.740)$ \\
\hline \multirow[t]{2}{*}{ Age } & $1.57 * * *$ & $1.74 * * *$ & $1.12 * * *$ & $1.11 * *$ & $0.78 * * *$ \\
\hline & $(1.431-1.730)$ & $(1.524-1.976)$ & $(1.043-1.195)$ & $(1.002-1.221)$ & $(0.731-0.824)$ \\
\hline \multirow[t]{2}{*}{ Age $\mathrm{x}$ Intervention } & & $0.82 * *$ & & & \\
\hline & & $(0.683-0.974)$ & & & \\
\hline \multirow[t]{2}{*}{ Male } & $0.62 * * *$ & $0.63 * * *$ & 1 & $1.72 * * *$ & $1.25^{* *}$ \\
\hline & $(0.465-0.826)$ & $(0.470-0.837)$ & $(0.815-1.235)$ & $(1.265-2.345)$ & $(1.046-1.495)$ \\
\hline \multirow[t]{2}{*}{ Single Orphan } & $4.54 * * *$ & $4.64 * * *$ & $0.66^{* *}$ & 1.3 & $0.59 * * *$ \\
\hline & $(2.816-7.315)$ & $(2.885-7.474)$ & $(0.452-0.979)$ & $(0.755-2.249)$ & $(0.419-0.818)$ \\
\hline \multirow[t]{2}{*}{ Double Orphan } & $12.55 * * *$ & $12.17 * * *$ & 0.75 & 1.8 & $0.25 * * *$ \\
\hline & $(5.349-29.466)$ & $(5.177-28.603)$ & $(0.401-1.393)$ & $(0.642-5.062)$ & $(0.139-0.455)$ \\
\hline \multirow[t]{2}{*}{ No Breakfast 08} & 1.26 & 1.28 & $0.76^{* *}$ & $0.52 * * *$ & $1.24 *$ \\
\hline & $(0.891-1.772)$ & $(0.907-1.805)$ & $(0.586-0.994)$ & $(0.334-0.817)$ & $(0.988-1.544)$ \\
\hline \multirow[t]{2}{*}{ Assistance 08} & 0.85 & 0.86 & 1.19 & $0.64 * *$ & 0.87 \\
\hline & $(0.588-1.218)$ & $(0.594-1.232)$ & $(0.923-1.536)$ & $(0.415-0.997)$ & $(0.699-1.084)$ \\
\hline \multirow{2}{*}{$\begin{array}{l}\text { Maternal Orphan } \\
\text { (self-report) }\end{array}$} & $0.05 * * *$ & $0.05 * * *$ & $1.53 * *$ & $0.07 * * *$ & $1.88 * * *$ \\
\hline & $(0.011-0.213)$ & $(0.011-0.217)$ & $(1.010-2.307)$ & $(0.009-0.494)$ & $(1.259-2.803)$ \\
\hline \multirow{2}{*}{$\begin{array}{l}\text { Paternal Orphan } \\
\text { (self-report) }\end{array}$} & $0.04 * * *$ & $0.04 * * *$ & 1.04 & & $3.48 * * *$ \\
\hline & $(0.016-0.125)$ & $(0.015-0.121)$ & $(0.741-1.454)$ & & $(2.516-4.805)$ \\
\hline \multirow{2}{*}{$\begin{array}{l}\text { Repeated St } 6 \\
(2009)\end{array}$} & 1.34 & 1.37 & 0.91 & 0.96 & $1.36^{* *}$ \\
\hline & $(0.914-1.972)$ & $(0.931-2.014)$ & $(0.665-1.245)$ & $(0.621-1.483)$ & $(1.032-1.797)$ \\
\hline \multirow[t]{2}{*}{ Baseline English Exam } & 0.99 & 1 & $0.86 * * *$ & $0.94 *$ & $1.14 * * *$ \\
\hline & $(0.944-1.045)$ & $(0.946-1.048)$ & $(0.824-0.896)$ & $(0.886-1.001)$ & $(1.103-1.181)$ \\
\hline \multirow[t]{2}{*}{ Baseline Maths Exam } & $0.95 *$ & $0.94 *$ & $0.85 * * *$ & $0.85 * * *$ & $1.14 * * *$ \\
\hline & $(0.888-1.008)$ & $(0.886-1.006)$ & $(0.807-0.893)$ & $(0.781-0.915)$ & $(1.092-1.183)$ \\
\hline \multirow[t]{2}{*}{ District } & $0.46^{* * *}$ & $0.46^{* * *}$ & 0.85 & 0.63 & 1.32 \\
\hline & $(0.307-0.693)$ & $(0.310-0.690)$ & $(0.438-1.638)$ & $(0.309-1.278)$ & $(0.823-2.116)$ \\
\hline Observations & 2,767 & 2,767 & 2,767 & 2,767 & 2,767 \\
\hline Number of Schools & 40 & 40 & 40 & 40 & 40 \\
\hline
\end{tabular}




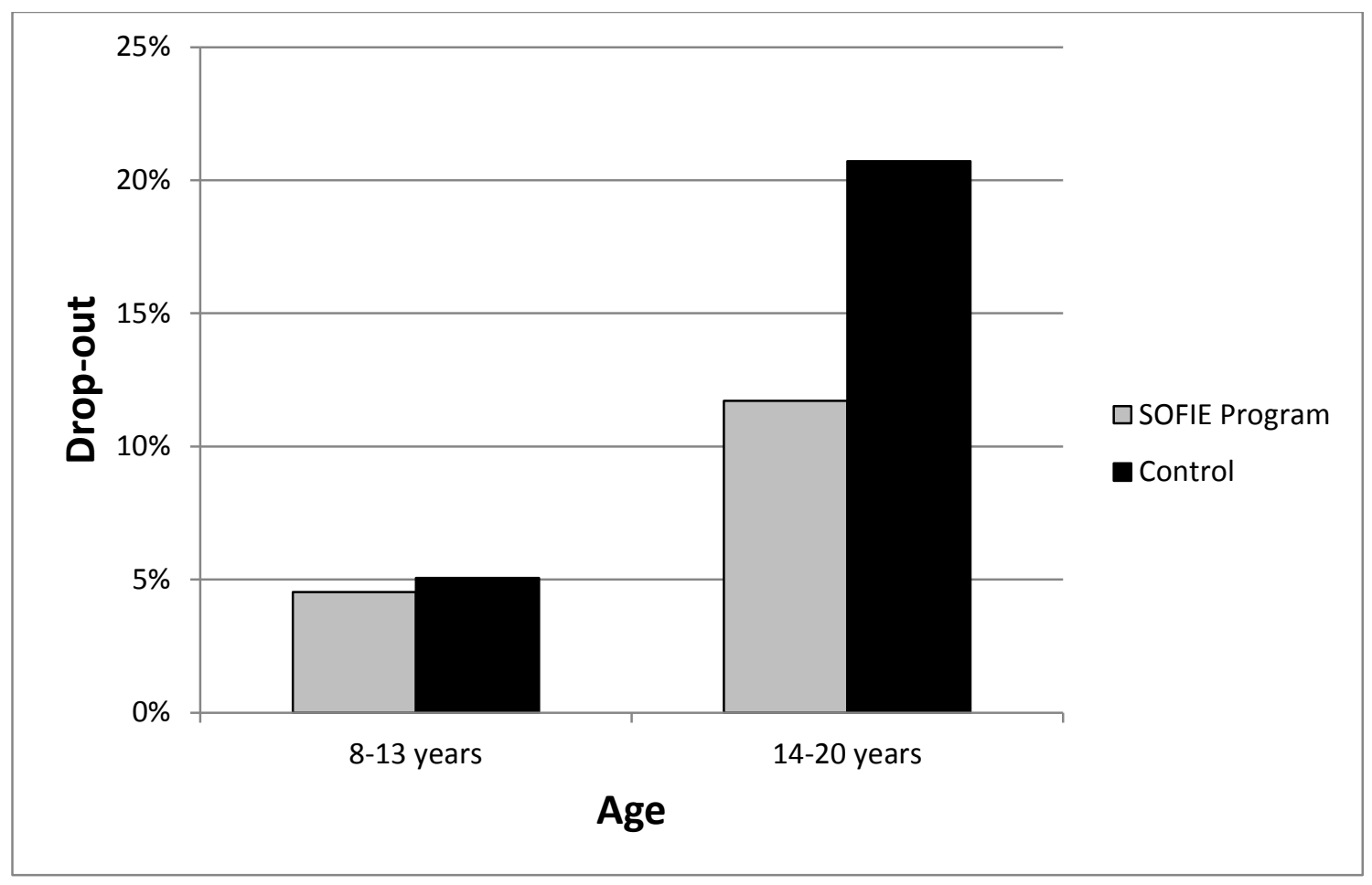

Figure 2. Program impact on dropout in different age groups.

Contrary to expectations, academic outcomes were somewhat better for children deemed at-risk by their communities than for children who were not deemed at-risk. This was the case in both intervention and control groups and thus was independent - not a result of - the intervention. Unadjusted estimates suggest that children deemed as at-risk were more likely to be promoted than their peers (Model 5). When controlling for variables such as orphan status and indices of poverty, adjusted estimates suggested that children in the at-risk group were also less likely to drop out of school (Model 2). One explanation for this finding is that the children who were perceived as being at-risk by their communities were not, in fact, those most at risk. Older children are most vulnerable to dropout but age was not used as a criterion for selection of at-risk children (refer back to Table 2 for observed criteria for at-risk group selection). 
Table 7. Regression equation estimates of the impact of the program on exam scores

\begin{tabular}{|c|c|c|c|}
\hline Outcome & $\begin{array}{c}\text { (6) } \\
\text { English }\end{array}$ & $\begin{array}{c}(7) \\
\text { Maths }\end{array}$ & $\begin{array}{c}(8) \\
\text { Supplementary }\end{array}$ \\
\hline \multicolumn{4}{|l|}{ Without Covariates: } \\
\hline Intervention & $\begin{array}{c}0.12 \\
(-0.479-0.709)\end{array}$ & $\begin{array}{c}0.63 \\
(-0.124-1.380)\end{array}$ & $\begin{array}{c}0.17 \\
(-0.332-0.679)\end{array}$ \\
\hline $\begin{array}{l}\text { Deemed at-risk by } \\
\text { community }\end{array}$ & $\begin{array}{c}-0.11 \\
(-0.438-0.221)\end{array}$ & $\begin{array}{c}0 \\
(-0.288-0.292)\end{array}$ & $\begin{array}{c}-0.16 \\
(-0.371-0.053)\end{array}$ \\
\hline Baseline English Exam & $\begin{array}{c}0.64 * * * \\
(0.596-0.685)\end{array}$ & $\begin{array}{c}0.30 * * * \\
(0.260-0.339)\end{array}$ & $\begin{array}{c}0.23 * * * \\
(0.202-0.260)\end{array}$ \\
\hline Baseline Maths Exam & $\begin{array}{c}0.36^{* * * *} \\
(0.313-0.415)\end{array}$ & $\begin{array}{c}0.53 * * * \\
(0.482-0.573)\end{array}$ & $\begin{array}{c}0.27 * * * \\
(0.239-0.305)\end{array}$ \\
\hline \multicolumn{4}{|l|}{ With Covariates: } \\
\hline Intervention & $\begin{array}{c}0.13 \\
(-0.506-0.766)\end{array}$ & $\begin{array}{c}0.59 \\
(-0.253-1.442)\end{array}$ & $\begin{array}{c}0.16 \\
(-0.254-0.575)\end{array}$ \\
\hline $\begin{array}{l}\text { Deemed at-risk by } \\
\text { community }\end{array}$ & $\begin{array}{c}0.24 \\
(-0.222-0.700)\end{array}$ & $\begin{array}{c}-0.15 \\
(-0.560-0.259)\end{array}$ & $\begin{array}{c}-0.18 \\
(-0.478-0.112)\end{array}$ \\
\hline Baseline English Exam & $\begin{array}{c}0.62 * * * \\
(0.579-0.668)\end{array}$ & $\begin{array}{c}0.29 * * * \\
(0.253-0.333)\end{array}$ & $\begin{array}{c}0.22 * * * \\
(0.196-0.253)\end{array}$ \\
\hline Baseline Maths Exam & $\begin{array}{c}0.34 * * * \\
(0.294-0.396)\end{array}$ & $\begin{array}{c}0.51 * * * \\
(0.467-0.558)\end{array}$ & $\begin{array}{c}0.26 * * * \\
(0.224-0.289)\end{array}$ \\
\hline Age & $\begin{array}{c}-0.36 * * * \\
(-0.443--0.274)\end{array}$ & $\begin{array}{c}-0.14 * * * \\
(-0.210--0.060)\end{array}$ & $\begin{array}{c}-0.19 * * * \\
(-0.239--0.131)\end{array}$ \\
\hline Male & $\begin{array}{c}0.60 * * * \\
(0.338-0.853)\end{array}$ & $\begin{array}{c}0.49 * * * \\
(0.261-0.717)\end{array}$ & $\begin{array}{c}0.45 * * * \\
(0.283-0.612)\end{array}$ \\
\hline Single Orphan & $\begin{array}{c}-0.11 \\
(-0.583-0.358)\end{array}$ & $\begin{array}{c}0.33 \\
(-0.090-0.745)\end{array}$ & $\begin{array}{c}-0.05 \\
(-0.348-0.255)\end{array}$ \\
\hline Double Orphan & $\begin{array}{c}-0.26 \\
(-1.058-0.535)\end{array}$ & $\begin{array}{c}0.37 \\
(-0.337-1.077)\end{array}$ & $\begin{array}{c}0.63^{* *} \\
(0.123-1.144)\end{array}$ \\
\hline No Breakfast 08 & $\begin{array}{c}0.02 \\
(-0.295-0.332)\end{array}$ & $\begin{array}{c}0.30 * * \\
(0.020-0.579)\end{array}$ & $\begin{array}{c}-0.01 \\
(-0.211-0.190)\end{array}$ \\
\hline Assistance 08 & $\begin{array}{c}-0.34 * * \\
(-0.656--0.033)\end{array}$ & $\begin{array}{c}-0.25^{*} \\
(-0.529-0.026)\end{array}$ & $\begin{array}{c}-0.42 * * * \\
(-0.616--0.217)\end{array}$ \\
\hline $\begin{array}{l}\text { Maternal Orphan } \\
\text { (self-report) }\end{array}$ & $\begin{array}{c}-0.46^{*} \\
(-0.989-0.061)\end{array}$ & $\begin{array}{c}-0.61 * * \\
(-1.074--0.144)\end{array}$ & $\begin{array}{c}-0.64 * * * \\
(-0.974--0.302)\end{array}$ \\
\hline $\begin{array}{l}\text { Paternal Orphan } \\
\text { (self-report) }\end{array}$ & $\begin{array}{c}-0.22 \\
(-0.634-0.202)\end{array}$ & $\begin{array}{c}0.1 \\
(-0.274-0.468)\end{array}$ & $\begin{array}{c}0.17 \\
(-0.094-0.441)\end{array}$ \\
\hline Repeated St 6 & 0.15 & -0.13 & 0.12 \\
\hline (2009) & $(-0.254-0.556)$ & $(-0.492-0.230)$ & $(-0.136-0.383)$ \\
\hline District & $\begin{array}{c}-0.37 \\
(-1.016-0.269) \\
\end{array}$ & $\begin{array}{c}-0.68 \\
(-1.527-0.175) \\
\end{array}$ & $\begin{array}{c}-1.27 * * * \\
(-1.684--0.848)\end{array}$ \\
\hline Observations & 2,767 & 2,767 & 2,767 \\
\hline Number of Schools & 40 & 40 & 40 \\
\hline
\end{tabular}


Table 7 presents estimates of the program impact on exam results. The intervention had no significant overall effect on performance in any of the three exams. There were also no significant interactions between the intervention on one hand and age, at-risk group or other child characteristics on the other. Overall, children deemed as atrisk performed similarly to children not deemed at-risk. Consistent with findings on academic progression, older children performed more poorly in all three exams. Exam scores were also poorer among maternal orphans and children from families who receive external financial assistance.

\subsection{Observed Statistical Power}

Statistical power to detect observed differences in dropout rates was relatively low. For the sub-sample of at-risk children dropout was $11.2 \%$ in the control group and $5.0 \%$ in the intervention group. With the final sample size including an average of 13 SOFIE club members per school and an observed intra-class correlation of 0.039 the estimated power to detect the observed difference in drop-out was $50 \%$. For the overall sample, dropout was $12.4 \%$ in the control group and $8.1 \%$ in the intervention group. With an average of 67 children in each school and an observed intra-class correlation of 0.026 the estimated power to detect this difference was $50 \%$.

\subsection{Process and Implementation Variables}

Overall, key program activities were consistently implemented in intervention schools (see Table 8). All 20 schools held frequent SOFIE club meetings, recruited buddies and held SOFIE committee meetings. Most schools kept a register and monitored at-risk pupils. Conversely, some activities were conducted in only a small number of schools including amending school policies, involvement of pupil representatives in 
SOFIE committee meetings and the conducting of community sensitization activities by the SOFIE committee. Of all process variables two were highly negatively correlated with dropout. Schools whose teachers received SOFIE training $(n=15)$ and schools that kept an up-to-date register of at-risk pupils $(\mathrm{n}=16)$ had the lowest dropout rates. Dropout was lowest (a mean of 5.2\%) among the 13 schools with both of these characteristics compared to a dropout rate double that (10.8\%) among the 7 intervention schools with one or neither of these two characteristics.

Table 8. Summary of process and implementation variables in 20 intervention schools.

\begin{tabular}{lcc}
\hline & Freq /20 \\
\hline Club Leader is Female & 6 \\
At-Risk Register maintained & 16 & \\
Teacher graded study guides every 2 weeks & 14 & \\
Club leader graded study guides* & 11 & \\
Additional homework by teacher for At-Risk & 12 & \\
children & & \\
At-Risk Child referred for counseling & 12 & \\
Community Sensitization Activities* & 14 & \\
Pupil representative attended SOFIE committee & 2 & \\
meetings* & 14 & \\
Monitoring and follow up of At-Risk pupils & 8 & \\
Fund raising and resource provision for At-Risk & & \\
children & 8 & \\
School policies amended to support At-Risk & & \\
Children & Mean & Range \\
\hline & 6.2 & $(2-10)$ \\
\hline Total number of buddies recruited* & 22.9 & $(20-31)$ \\
Age of club leader (years) & 30.4 & $(18-36)$ \\
Number of club meetings held & 4.8 & $(2-6)$ \\
Number of male SOFIE committee members* & 3.3 & $(1-7)$ \\
Number of female SOFIE committee members* & 8.1 & $(3-13)$ \\
Total number of SOFIE committee members* & 4.1 & $(0-8)$ \\
Number of SOFIE committee meetings held* & \\
Number of SOFIE committee meetings attended by & 0.1 & $(0-2)$ \\
PEA* & & \\
Number of SOFIE committee meetings attended by & 0.2 & $(0-1)$ \\
pupil representative* & & \\
\hline
\end{tabular}

*Missing data for 4 schools (PEA attendance at committee meetings), 2 schools (club leader marking study guide) or 1 school (all other indicated variables). 
Qualitative data relating to the process and implementation of the SOFIE project are described in detail elsewhere (Jere, 2011). Here we focus on data which have the potential to illuminate the findings from the impact evaluation. A key question concerned the surprising finding that the SOFIE project reduced dropout for students who were not considered to be vulnerable and were not explicitly targeted by the intervention. Four lines of evidence speak to the ways in which the program could have achieved such spillover effects.

First, there is some qualitative evidence to suggest that the SOFIE program helped to engender a culture of academic persistence in intervention schools which may have had effects beyond those among the at-risk children in SOFIE clubs. During focus group discussions school staff and community representatives spoke of their involvement in the project as a matter of pride and told us that pupils were keen to be selected for SOFIE clubs. In this way, mere inclusion in the project - regardless of specific activities - may have provided additional motivation for students.

Second, during evaluation workshops, stakeholders from the majority of schools (17/20) agreed that pupils deemed as at-risk generally learnt collaboratively with others, including their buddies and classmates, thus increasing access to SOFIE resources beyond the immediate at-risk group. During interviews, several at-risk pupils spoke of sharing their study guides with fellow pupils and classmates. In addition, several teachers at the evaluation workshop acknowledged that they made use of the study guides in preparing their own class lessons. Furthermore, the majority (60\%) of buddies recruited to provide peer support were drawn from Class 6 and thus form part of the not-at-risk group included in data collection. The buddies would have benefited from club activities 
and resources in similar ways to the children deemed as at-risk. Some schools reported deliberately recruiting buddies who were vulnerable but were not selected as part of the selected at-risk group in order to help increase the number of program beneficiaries.

Third, the program may have led to a general awareness of the support required for vulnerable children. For example, across the majority of intervention schools, participants reported a notable improvement in record-keeping, monitoring of pupil attendance and follow-up of all pupils, not just those in the SOFIE clubs. Eighteen schools had kept up-to-date class registers and 15 schools had regularly recorded reasons for absence. In this way, it was less easy for habitual absentees, or those who had temporarily withdrawn, to slip through the net and to drop out permanently.

Fourth, stakeholders from several schools at the evaluation workshop spoke of changes made to school-level policies and practices as a result of SOFIE training to help keep children in school and to promote the inclusion of vulnerable children; a few spoke of schools becoming more "child-friendly." Five of the intervention schools addressed the issue of school costs by making uniform no longer compulsory or by giving households enough time to buy a uniform without excluding the child. Several schools also re-visited their discipline policies to ensure that children were not prevented from learning during class time and made attempts to encourage attendance and participation amongst pupils, such as through choirs, drama displays and sporting activities. It seems likely that such initiatives would support a wider number of pupils beyond the at-risk group.

\subsection{Cost}

The recurrent government expenditure in Malawi per student in primary education 
was amongst the lowest in Sub-Saharan Africa in 2007/2008 at around MK3000 (USD 20) (World Bank, 2010 p.32) and the cost of the SOFIE intervention needs to be considered in relation to this low expenditure in order to assess its potential for sustainability if scaled up. The overall financial cost to the program for the training and additional learning materials provided is estimated at USD 43 for each pupil deemed as at-risk. However, it may be more appropriate to calculate the expenditure per enrolled pupil for comparison with the per-pupil government education expenditure and because evidence of spillover effects in this study suggests that all children in class six could be considered beneficiaries. The cost per enrolled pupil would then be reduced to approximately USD 8.5. This figure could be reduced if the cost of notebooks and pens could be subsumed within guidelines for school-level decision making about grants from the Malawi Government's Direct School Support Program, the self-study guides were revised to reduce length without reducing quality and reused for up to (say) five years and the wind-up radios supplied to all government primary were shared more widely within the schools. However, the above estimates exclude the full economic costs of developing the additional learning materials and their distribution, of staff time for training and for leading SOFIE clubs

\section{Discussion}

Overall, the SOFIE program was successful in reducing school dropout. It is likely that some of the children who stayed in school as a result of the program were promoted to Class 7 and others repeated Class 6, although there was no significant effect of the program on either repetition or promotion separately. There was less robust 
evidence that the program improved Mathematics achievement among children deemed as at-risk and no evidence of improvements in English achievement. It is difficult to say with certainty which of the program components were critical for success but we noted that dropout was lowest in schools whose teachers had attended the program training and who kept up-to-date at-risk registers.

It is helpful to put this result in the context of other similar evaluations. Our study found that dropout was cut in half from a level of around $12 \%$ in the control group. This is similar to findings from an evaluation of a program to improve literacy instruction in Kenya (Jukes et al., 2014), which found that dropout was reduced from $9 \%$ to $4 \%$ due to improved education quality. Among other evaluations examining the impact on dropout from school in less developed countries, the majority involved cash transfers to families or school committees (Kremer, Brannen, \& Glennerster, 2013). A conditional cash transfer program in Morocco reduced dropout from 10\% to 3\% (Benhassine, Devoto, Duflo, Dupas, \& Pouliquen., 2014). A private school voucher program in Colombia increased children's chances of reaching $8^{\text {th }}$ grade by $10 \%$ (Angrist et al., 2002). Cash grants to schools committees have also been successful, reducing dropout by 1.3 percentages points in Niger (Beasley, 2013) and 1.6 percentage points in Mexico (Gertler, Patrinos, \& Rodriguez-Oreggia, 2012). Health interventions have also been successful in reducing dropout. For example, an early childhood malaria prevention program in the Gambia led to children staying in school for an average of one year longer (Jukes et al., 2006). Our results are important because they represent one of very few evaluations of a program designed to reduce dropout by providing support to improve children's learning. 
Two surprising findings of the study related to the performance of the group of children identified as at-risk. First, at-risk children in both control and intervention schools were somewhat less likely to drop out of school than children not at risk, which suggests the community did not use the most relevant criteria for identifying at-risk children. The main criterion used to select the group was orphanhood. However, data suggest that orphans were not at greater risk of dropping out than other children. It is possible that orphanhood provides a visible indication of vulnerability which attracts support from community and organizations, the so-called "lucky orphan syndrome" (Schenk, 2009). By contrast, age was not used as a criterion for identifying the children at-risk, although our data show that older age was the most reliable predictor of both dropout and poor achievement. Repeating a grade at school, which is indirectly related to age, was suggested as a criterion for identifying children at-risk but there was no evidence that communities placed much emphasis on this criterion. Qualitative data pointed to the difficulty in selecting a small number of pupils to take part in the SOFIE clubs. Failure to target other at-risk children might also be due to the larger schools being unable to recruit all the potentially vulnerable children onto the program. It is also worth noting that, during training workshops for communities, orphanhood was listed as potential criterion for selecting children at-risk of dropout whereas age was not.

The second surprising finding was that the program reduced dropout for children who were not directly targeted with project activities as well as those who were so targeted. There was no significant difference in program impact between at-risk children and children not at risk. In fact, the only evidence of differential program impact was related to age in that the SOFIE program reduced dropout of older children to the greatest 
extent. It seems then that the program failed to target the most vulnerable children in its initial selection procedures, but the benefits of the program somehow found their way to these children nevertheless.

One explanation of the program's effect on children not directly targeted is that any measured impact on outcomes was due to the act of being evaluated. The possibility of such a Hawthorne effect was acknowledged and addressed at the design stage: interaction with the program evaluators was kept to a minimum at both control and intervention schools with the same number of visits and identical data collection activities in all schools, with the exception of activities to collect qualitative data, which were limited to the four case study schools. A genuine spillover effect is possible. It may have resulted from specific program components reaching other children in the school, suggesting that these components are relatively easy to implement. This was suggested by several lines of qualitative data (see Section 3.5) including: the program may have led to targeted children working collaboratively with and supporting the learning of buddies and other pupils not including in the SOFIE clubs; it may have changed teacher practices in relation to all children; and it may influenced some school-level policies and practices to become more inclusive and to encourage children to continue with their schooling rather than drop out. In addition, the program may have had indirect effects on the psychology of students. Qualitative data suggest the program may have engendered a culture of academic persistence throughout the school. It is possible that the mere presence of a new program would have motivated some students to stay in school.

It is also possible that spillover effects extended from intervention to control schools (Crouch et al., 2009). In some cases, control schools were only $4 \mathrm{~km}$ away from 
intervention schools and SOFIE club children may have shared resources with pupils from other schools. If such spillover effects were present, the program effect sizes reported here would underestimate the true impact of the program.

From our process evaluation data, the mechanisms of the program effect cannot be identified with the same degree of certainty as the effect itself. Thus, without further evidence we cannot say for sure how the program had its effect and it is difficult to be certain that the program would have been successful if it had not been evaluated. This is one limitation of the current evaluation. A second limitation is that statistical power was less than expected. Consequently, we cannot be sure whether the observed improvement in mathematics achievement was a genuine program effect or not. A third limitation is that the children deemed as at-risk within the control group were selected retrospectively based on observable characteristics which may not accurately represent the selection criteria that would have been used by communities. This limitation is not a concern for the main findings of the study, which relate to overall program effects, but may have affected sub-group effects among children deemed as at-risk.

If the program effect found here is genuine, it is useful to consider the other contexts in which such a program would be successful. Many of the contextual factors important for the success of the SOFIE program are common across sub-Saharan Africa. The program was most successful for children who were over-age. Late enrolment and repetition is common on the continent (Sabates, Akyeampong, Westbrook, \& Hunt, 2010) leading to large numbers of children who are older than peers in the same grade level. Many of the contextual conditions we identified in this study were also found in a review of barriers to schooling for children affected by HIV and AIDS across sub-Saharan 
Africa (Pridmore, 2008). First, this review found that intra-household discrimination and lack of encouragement for the education of orphans and vulnerable children was common across sub-Saharan Africa. Data suggest that the extra support and encouragement for vulnerable children was a key part of the success of the SOFIE program. Second, schoollevel policies were found to be unsupportive of orphans and vulnerable children in many African countries. This was the case in Malawi, providing one avenue by which the project could help support vulnerable children. Qualitative and process data suggest that schools changed their policies and practices to be more inclusive as a result of the SOFIE program.

Third, loss of social cohesion was found to be common in HIV-stressed communities in sub-Saharan Africa, although exceptions were found of resilient communities where the extended family held up under the stress of the HIV epidemic. Lack of social cohesion may have provided the opportunity for the SOFIE project to have an impact by providing support to children that the community were unable to help. Conversely, it is possible that the accusations of favoritism in selection of program beneficiaries could have resulted from lack of social cohesion in the community.

Finally, part of the success of the program may have rested on children's natural tendency to work cooperatively with their peers. Cooperation is a fundamental aspect of human behavior (Nowak, 2006) but is particularly common in collectivist African cultures (Jukes et al., in 2013; Jukes \& Grigorenko, in prep; Serpell, 2011).

Our overall conclusion from these findings is that the SOFIE project was successful in reducing dropout and such projects have the potential to benefit vulnerable children across sub-Saharan Africa. In future projects, care should be taken when 
identifying vulnerable children as program beneficiaries. It may be that the most visible indicators of vulnerability are not always the most reliable. Careful analysis of the nature of vulnerability is required. Once vulnerable children have been accurately identified a program of flexible learning and support may be an effective way of promoting the education of vulnerable children to help achieve goals of equity in education, such as those proposed for post-2015 education goals (UNESCO, 2014). 


\section{Acknowledgements}

The SOFIE Project was funded by the ESRC-DFID Joint Scheme and all members of the SOFIE research team contributed to the design and development of the studies in Malawi and Lesotho. The study was developed in collaboration with Mr. Chris Yates (Institute of Education, University of London), who led the development of the self-study learnerguides. The case studies in Malawi were designed and carried out, and the intervention model adapted to the country context, implemented and evaluated, by Dr. Kate Jere (formerly Moleni) from the Centre for Educational Research and Training, University of Malawi and by Dr. Thabiso Nyabanyaba from the Institute of Education, National University of Lesotho. Dr. Ephraim Mhlanga from the South African Institute for Distance Education provided expertise on open, distance and flexible learning initiatives in the African Region. Further information on this study can be found at http://sofie.ioe.ac.uk 


\section{References}

Andrews, G., Skinner, D., \& Zuma, K. (2006). Epidemiology of health and vulnerability among children orphaned and made vulnerable by HIV/AIDS in sub-Saharan Africa. Aids Care-Psychological and Socio-Medical Aspects of Aids/Hiv, 18(3), 269-276.

Angrist, J., Bettinger, E., Bloom, E., King, E., Kremer, M., \& Saavedra, J. (2002). Vouchers for Private Schooling in Colombia: Evidence from a Randomized Natural Experiment," American Economic Review, 92(5), 1535-1558.

Beasley, E., and Elise Huillery. . (2013). School Resources, Behavioral Responses and School Quality: Short-Term Experimental Evidence from Niger. Working Paper.

Benhassine, N., Devoto, F., Duflo, E., Dupas, P., \& Pouliquen., V. (2014). Turning a Shove into a Nudge? A 'Labeled Cash Transfer' for Education. NBER Working Paper.

Bennell, P. (2005). The Impact of the AIDS Epidemic on the Schooling of Orphans and Other Directly Affected Children in Sub-Saharan Africa. Journal of International Development Studies, 41(3), 467-488.

Bhargava, A. (2005). AIDS epidemic and the psychological well-being and school participation of Ethiopian orphans. Psychology, Health \& Medicine, 10(3), 263275.

Boler, T., \& Carroll, K. (2003). Addressing the educational needs of orphans and vulnerable children: Policy \& Research: issue 2. London: Save the Children/ActionAid International (UK working group on education and HIV/AIDS).

Boler, T., \& Jellema, A. (2005). Deadly Inertia: A Cross-country Study of Educational Responses to HIV/AIDS. Brussels: Global Campaign for Education.

Carr-Hill, R., Katabaro, K. J., Katahoire, A. R., \& Oulai, D. (2002). The Impact of HIV/AIDS on Education and Institutionalizing Preventive Education. Paris: UNESCO.

Craig, P., Dieppe, P., Macintyre, S., Michie, S., Nazareth, I., \& Petticrew, M. (2008). Developing and evaluating complex interventions: the new Medical Research Council guidance. BMJ, 337:a1655

Crouch, L., Korda, M., \& Mumo, D. (2009). Improvements in Reading Skills in Kenya: An Experiment in the Malindi District: USAID.

Dlamini, K. (2005). Circles of Support: children's voices. Johannesburg.

Foster, C., \& Williamson, J. (2000). A review of current literature on the impact of HIV/AIDS on children in sub-Saharan Africa. Aids, 14, S275-S284.

Gertler, P., Patrinos, H. A., \& Rodriguez-Oreggia, E. (2012). Parental Empowerment in Mexico: Randomized Experiment of the 'Apoyos a La Gestion Escolar (AGE)' in Rural Primary Schools in Mexico. Working Paper.

Government of Malawi. (2005). National Plan of Action for Orphans and other Vulnerable Children 2005-2009.

Hepburn, A. E. (2001). Primary Education in Eastern and Southern Africa: increasing access for orphans and other vulnerable childern in AIDS-affected areas. Durham: Duke University, Terry Sanford Institute of Public Policy.

Ishikawa, N., Pridmore, P., Carr-Hill, R., \& Chaimuangdee, K. (2010). Breaking down 
the wall of silence around children affected by AIDS in Thailand to support their psychosocial health. AIDS Care, 22 (3), 308-313.

Jere, C. M. (2008). Factors influencing access and retention in primary schooling for children and young people affected by HIV and AIDS: Case studies from rural Malawi. London: Institute of Education, University of London.

Jere, C. M. (2011). Developing, implementing and evaluating the SOFIE model: Supporting increased educational access for vulnerable pupils in rural Malawi. London: Institute of Education, University of London. Available at http://sofie.ioe.ac.uk/publications/MalawiFinalReport.pdf)

Jukes, M. C. H., Dubeck, M. M., Halliday, K. E., Turner, E. L., Wolf, S., Brooker, S. J., \& Zuilkowski, S. S. (2014). The Impact of an enhanced literacy instruction program on student achievement and dropout in Coastal Kenya Working Paper.

Jukes, M. C. H., \& Grigorenko, E. L. (in prep). The impact of school attendance and urban migration on cognitive function and indigenously defined measures of child development in the Gambia.

Jukes, M. C. H., Pinder, M., Grigorenko, E. L., Smith, H. B., Walraven, G., Bariau, E. M., Sternberg, R. J. Drake, L. J., Milligan, P., Cheung, Y. B., Greenwood, B. M. Bundy, D. A. P. (2006). Long-term impact of malaria chemoprophylaxis on cognitive abilities and educational attainment: Follow-up of a controlled trial. Plos Clinical Trials, 1(4).Jukes, M. C. H., Simmons, S., \& Bundy, D. A. P. (2008a). Education and vulnerability: the role of schools in protecting young women and girls from HIV in southern Africa. Aids, 22, S41-S56.

Jukes, M. C. H., Simmons, S., \& Bundy, D. A. P. (2008b). Educational access and HIV prevention: Making the case for education as a health priority in sub-Saharan Africa. Cambridge, MA: Joint Learning Initiative on Children and HIV/AIDS)

Jukes, M. C. H., Zuilkowski, S. S., Okello, G., \& Harris, P. (2013). "Healthy skepticism: Do adults trust health information from children in rural Kenya?" International Perspectives in Psychology: Research, Practice, Consultation 2(3): 164-180.

Kelly, M. J. (2000). Planning for education in the context of HIV/AIDS. Paris: UNESCO: International Institute for Educational Planning.

Kremer, M., Brannen, C., \& Glennerster, R. (2013). The Challenge of Education and Learning in the Developing World. Science, 340, 297-300. doi: $10.1126 /$ science. 1235350

Lewin, K. M. (2007). Improving Access, Equity and Transitions in Education: Creating a Research Agenda, CREATE Pathways to Access Series no. 1. Brighton: University of Sussex, Centre for International Education.

Luellen, J. K., Shadish, W. R., \& Clark, M. H. (2005). Propensity Scores : An Introduction and Experimental Test. Evaluation Review, 29(530-558).

Ministry of Education Science and Technology. (2010). Education Statistics 2010. Malawi: Department of Education Planning, Ministry of Education Science and Technology, Education Management Information System (EMIS)

Murphy, P. (1993). Costs of an Alternative Form of Second-Level Education in Malawi. Comparative Education Review, 37(2), 107-122.

Nowak, M. A. (2006). Five Rules for the Evolution of Cooperation. Science, 314(5805), 1560-1563.

NSO (2000). Malawi Demographic and Health Survey 2000. Calverton, Maryland: 
National Statistical Office (Malawi) and ORC Macro.

NSO (2005). Malawi Demographic and Health Survey 2004 Calverton, Maryland:

National Statistical Office (Malawi) and ORC Macro.

NSO, \& UNICEF. (2007). Malawi Multiplier Indicator Cluster Survey (MCIS):

Preliminary Report: National Statistics Office, Zomba; UNICEF.

QSR International Pty Ltd. (2008). Qualitative data analysis software; QSR International Pty Ltd. Version 8, 2008.

Pridmore, P. (2007). The Impact of health on education access and achievement: A crossnational review of the research evidence, CREATE Pathways to Access, Research Monograph no.2. . University of Sussex, Centre for International Education: Consortium for Research on Educational Access, Transitions and Equity (CREATE).

Pridmore, P. (2008). Access to conventional schooling for children and young people affected by HIV and AIDS in sub-Saharan Africa: a cross-national review of recent research evidence. London: Institute of Education, University of London.

Pridmore, P., \& Jere, C. M. (2011). Disrupting Patterns of Educational Inequality and Disadvantage in Malawi. Compare: a Journal of Comparative and International Education, 41(4).

Pridmore, P., \& Yates, C. (2005). Combating AIDS in South Africa and Mozambique: The Role of Open, Distance, and Flexible Learning (ODFL). Comparative Education Review, 49(4).

Rispel, L. (2006). Education Sector Responses to HIV and AIDS: Learning from Good Practices in Africa. London: Commonwealth Secretariat.

Royston, P. (2004). Multiple imputation of missing values. The Stata Journal, 4, 227 241.

Sabates, R., Akyeampong, K., Westbrook, J., \& Hunt, F. (2010). School Drop out: Patterns, Causes, Changes and Policies. Paris: UNESCO.

Schenk, K. D. (2008). What have we learnt? A review of evaluation evidence on community interventions providing care and support to children who have been orphaned and rendered vulnerable.: The Joint Learning Initiative on Children and HIV/AIDS (JLICA)

Schenk, K. D. (2009). Community interventions providing care and support to orphans and vulnerable children: a review of evaluation evidence. Aids CarePsychological and Socio-Medical Aspects of Aids/Hiv, 21(7), 918-942.

Schochet, P. Z., \& Burghardt, J. (2007). Using propensity scoring to estimate programrelated subgroup impacts in experimental program evaluations. Evaluation Review, 31(2), 95-120.

Serpell, R. (2011). Social Responsibility as a Dimension of Intelligence, and as an Educational Goal: Insights From Programmatic Research in an African Society. Child Development Perspectives, 5(2), 126-133.

Sherr, L., Varrall, R., Mueller, J., \& One, J. W. (2008). A systematic review on the meaning of the concept 'AIDS Orphan': confusion over definitions and implications for care. Aids Care-Psychological and Socio-Medical Aspects of Aids/Hiv, 20(5), 527-536.

Skinner, D., Tsheko, N., Mtero-Munyati, S., Segwabe, M., Chibatamoto, P., Mfecane, S., et al. (2006). Towards a Definition of Orphaned and Vulnerable Children. AIDS 
and Behaviour, 10(6), 619-626.

StataCorp. (2009). Stata Statistical Software: Release 11. College Station, TX:: StataCorp LP.

Streuli, N., \& Moleni, C. M. (2007). Education, HIV and AIDS in Malawi: the role of open, distance and flexible learning. SOFIE project: Institute of Education, University of London.

UNAIDS. (2001). Investing in our Future: Psychosocial support for children affected by HIV/AIDS: A Case Study in Zimbabwe and the United Republic of Tanzania. New York.

UNESCO. (2011). EFA Global Monitoring Report: The hidden crisis: Armed conflict and education. Paris: UNESCO.

UNESCO. (2014). Joint Proposal of the EFA Steerting Committee on Education Post2015. Oman: UNESCO.

Van Buuren, S., Boshuizen, H. C., \& Knook, D. L. (1999). Multiple imputation of missing blood pressure covariates in survival analysis. Statistics in Medicine, 18(6), 681-694.

World Bank. (2010). The Education System in Malawi. Washington DC: The World Bank.

Yates, C. (2008). Keeping children in school: a review of open education policies in Lesotho and Malawi. London: Institute of Education, University of London. 
Appendix: Guidance given to communities on criteria for selecting 'at-risk' pupils

\section{Family/Household Background}

- A child who has lost one or both parents and lacks proper care and support

- A child who staying with elderly grandparent(s)

- A child staying in a sibling-headed household

- A child who is caring for sick parents or guardians

- A child coming from a household affected by HIV and AIDS.

\section{School-related}

- previous grade repetition

- irregular attendance or continuous absence for more than 3 weeks

- poor performance in class work and tests.

- Low level of concentration and participation in class

\section{Personal}

- Social isolation/inability to make friends/suffer stigma or discrimination.

- Coming to school hungry/looking uncared for/poorly dressed.

- Poor health or physical impairment

- Not having adequate materials able to organize own learning - ie. lack of pen/notebook/textbook/uniform.

The above criteria are intended as guidelines only. These criteria are to assist in the selection of vulnerable children to be placed on an 'at-risk' register and join SOFIE clubs for additional learning support. Using these criteria should help schools identify children known to be vulnerable and at risk of dropping out of school permanently or repeating a grade.

\section{Remember: the focus of the SOFIE project is to assist schools to increase pupils' access and participation in schooling, reduce dropout and improve learning.}

Selection of these vulnerable children should not be done by just one person. It is recommended that a small SOFIE committee be set up to oversee the selection process (this could include the same people that selected the youth leaders).

Initially, no more than 10 pupils should be selected. If there are fewer pupils, this is fine! You may not be able to identify all vulnerable children at the start of the school year. Others can be identified and asked to join SOFIE clubs as time goes by. Make sure that you do not rush to choose many pupils, but keep some resources in hand for those that may join later.

\section{Remember: Children can become vulnerable and at risk of dropping out or repeating at any time. A child's circumstances can quickly change - schools have to be aware of such changes.}


National Policy for Orphans and other Vulnerable Children

The policy defines an orphan as:

'a child who has lost one or both parents because of death and is under the age of 18'.

A vulnerable child is:

' a child who has no able parents or guardians, staying alone or with elderly grandparents or lives in a sibling-headed household, has no fixed place and lacks access to health care, material and psychological care and has no shelter'. 